\title{
Perceptions of World Englishes Accents in English Phonetics Instruction of China
}

\author{
Zhengwei Pei (Corresponding author) \\ School of Foreign Studies, Nanjing Agricultural University, 1 Weigang, Xuanwu District, Nanjing, Jiangsu 210095, P.R. China \\ E-mail: wei@njau.edu.cn \\ Yanhong Xing \\ School of Foreign Studies, Nanjing Agricultural University, 1 Weigang, Xuanwu District, Nanjing, Jiangsu 210095, P.R. China \\ E-mail: yanhong771@126.com
}

\author{
Received: 07-03-2016 \\ Accepted: 11-05-2016 \\ Advance Access Published: May 2016 \\ Published: 01-07-2016 \\ doi:10.7575/aiac.ijalel.v.5n.4p.183 \\ URL: http://dx.doi.org/10.7575/aiac.ijalel.v.5n.4p.183
}

The study is financed by research grants (13YYB008; 14jsyw-15) from Jiangsu Planning Office of Philosophy and Social Science as well as Philosophy and Social Sciences Federation of Jiangsu Province, China.

\begin{abstract}
With the notion of World Englishes (WE) accepted in the academia, the past decade has witnessed ten studies or so conducted to scrutinize how English learners of China perceptually evaluate English varieties. Those studies, however, seldom explore the juncture between learners' attitudes toward accent varieties of English and their expectations of English phonetics instruction. Additionally, they primarily draw quantitative data from surveys of large samples without providing in-depth viewpoints from learners themselves. This study aimed to investigate Chinese tertiary-level English learners' attitudes toward WE accents and how they view accents situated in English phonetics instruction with crossvalidated research methods including an accent recognition test, an attitudinal experiment, a questionnaire survey, and semi-structured interviews. Its participants were 64 sophomore English majors at a Chinese university; the accents examined were American English (AmE), British English (BrE), China English (ChE), Australian English, Indian English, and Korean English. Results indicate that students could recognize AmE and BrE better than other accents and that they identified with BrE most, but preferred to imitate AmE and welcome Americans as their phonetics teachers. Results also show students' propensity for setting a native speaker norm, rather than adopting ChE as a model, at phonetics class. Based on the findings, the study concluded that nowadays teachers for English majors in China still need to adhere to the native speaker model in English phonetics instruction, and meanwhile, expose their students to various WE accents in order to facilitate their English phonetics learning and cultivate their awareness of WE.
\end{abstract}

Keywords: English majors, attitudes, expectations, World Englishes accents, English phonetics instruction

\section{Introduction}

In the trend of globalization coupled with localization, the notion of World Englishes (hereafter WE) has gradually been accepted, and different varieties of English are taking shape around the world. Among what tells apart these varieties, phonetic features are obviously the most discernable, as WE accents soon leave diverse impressions on a human ear. In the past decade, approximately ten studies have been conducted to scrutinize how English learners in China perceptually evaluate English varieties. They, however, rarely explore the juncture between learners' attitudes toward WE accents and their expectations of English phonetics instruction. Besides, they primarily draw quantitative data from surveys of large samples without providing in-depth viewpoints from learners themselves.

In this paper, we report a study built on cross-validated research methods, i.e. an accent recognition test, an attitudinal experiment, a questionnaire survey, and semi-structured interviews. The study aims to ascertain: 1) to what extent tertiary-level English learners in China can recognize WE accents; 2) which accent they identify with most and prefer to imitate over their English phonetics learning; and 3) how they view WE accents situated in English phonetics instruction.

\section{Methodology}

\subsection{Participants}

The participants were 64 sophomore English majors, undergraduates majoring in the discipline of English, from Nanjing Agricultural University (NAU) in Nanjing, China. They were aged from 18 to 22 ( $M=20$ years). The majority of them were females $(\mathrm{N}=58,90.6 \%)$, reflecting a gender imbalance typical among students of language in China.

\subsection{Procedure}

We carried out the study in two phases. Phase One lasted for half an hour in a language laboratory. It comprised three tasks: 1) an accent recognition test: participants listened to six WE accents and then judged the nationality of each 
accent; 2) an attitudinal experiment: participants rated their impressions of each accent (e.g., pleasant) and its speaker (e.g., reliable) as reflected by 18 traits (see Table 2), and then decided to what degree they identified with this accent and desired to imitate it in their phonetics learning on a 6-point scale from 1 'not at all' to 6 'very'; and 3) a survey: participants gave viewpoints about WE accents and English phonetics instruction. After the completion of Phase One, all the questionnaires were reclaimed, checked and counted as valid. Phase Two was arranged after the main results of Phase One had come out, for which 18 participants were purposefully selected to take face-to-face interviews.

\subsection{Materials}

For the accent recognition test and the attitudinal experiment, we prepared six accents representing three WE circles: American English (AmE), British English (BrE), and Australian English (AuE) from inner circle (IC) countries, Indian English (InE) from outer circle (OC) countries, as well as China English (ChE) and Korean English (KoE) from expanding circle (EC) countries. The accent samples were derived from Speech Accent Archive (Weinberger, 2014), produced by six speakers reading the same passage but in dissimilar accents. To guarantee their typicality, we went through three steps:

1) Choose the samples which were read at a moderate speed by females, clear and free of slips of the tongue, with AmE and BrE respectively manifested in General American (GA) and Received Pronunciation (RP);

2) Check them against the literature regarding phonetic discrepancies among the six accents. For instance, $/ \mathrm{s} / \mathrm{and} / \mathrm{\theta} /$ in RP are separately pronounced as /a/ in GA and aspirated / $t$ / in the Indian accent (Dai, 2000; Ding, 1992);

3) Invite native speakers, most of whom were English teachers or international students at NAU, to judge sample representativeness in light of their intuition and expertise.

For the survey, we devised a questionnaire to obtain participants' background information (e.g., age, gender, experiences of traveling abroad) and perceptions of WE accents in English phonetics instruction. The written items for the aforementioned accent recognition test and attitudinal experiment were also attached to the questionnaire. They were adapted from Bayard et al. (2001) and Ladegaard and Sachdev (2006). For the semi-structured interviews, specific questions were addressed to those selected students with the purpose of eliciting their attitudes toward WE accents and reasons behind the scene.

\section{Results and discussion}

\subsection{Recognition of WE accents}

We know from the percentages of correct responses to the accent recognition test that within the six accents, AmE received the highest accuracy $(65.6 \%)$, followed by $\mathrm{BrE}(54.7 \%)$. AuE as another IC accent was not so accurately recognized as $\mathrm{AmE}$ and $\mathrm{BrE}$ and ranked fifth (32.8\%). The only OC accent InE obtained the lowest accuracy rate (31.3\%). ChE (37.5\%) was not recognized as accurately as expected. It was ranked fourth, lower than KoE (42.2\%).

Prior studies targeting English and non-English majors in China (e.g., Gao \& Lin, 2008; Xu \& Gao, 2014) have yielded similar findings that $\mathrm{AmE}$ is easier to be recognized than other IC accents, such as $\mathrm{BrE}$ and $\mathrm{AuE}$, and $\mathrm{InE}$ is not recognized well. Nevertheless, they differ from the present study in that they find $\mathrm{ChE}$ the most accurately recognizable among the WE accents under study including AmE and BrE, probably because they merely examine ChE, while ours involved two EC varieties - $\mathrm{ChE}$ and $\mathrm{KoE}$. Of our participants, 28.1\% mistook ChE for KoE and 23.4\% mistook it for InE. When confronted with two EC accents, the participants felt it hard to distinguish them.

Our results demonstrate that English majors were familiar with $\mathrm{AmE}$ and BrE, but not with OC accents and other IC accents. They were also not so sensitive to the typical pronunciation features of $\mathrm{ChE}$, although living in China and surrounded by classmates who spoke ChE. Lack of exposure to an array of WE accents could explain their inability to accurately recognize far more accents than AmE and BrE. It is known from our survey that most participants did not get abroad. As for the nine participants $(14.1 \%)$ who did sightseeing in foreign countries for about half a month, their chances to chat with locals and feel their accents were very slim. On university campus, student exposure was also limited to AmE or BrE. In preparing the sample of $\mathrm{KoE}$ accent, we invited two Koreans - a boy studying at NAU as an international student and a girl working on her Master's degree in an American university in Pennsylvania - and simultaneously presented them $\mathrm{ChE}$ and $\mathrm{KoE}$ samples. As a result, they succeeded in singling out the Korean accent. The girl even specified how the Koreans pronounce /a/, /o/ and /i/ differently from the Chinese and how they are less skilled at liaison based on her personal experiences of meeting people from these two countries. Xu and Gao's (2014) study in China, again, testifies to the role of wide exposure in recognizing WE accents. They surveyed over 750 university student volunteers before and after four international events (i.e., Beijing Olympic Games, Shanghai World Expo, Guangzhou Asian Games, and Shenzhen Universiade) taking place between 2008 and 2011 in China, discovering that the recognition accuracy rates for five varieties of WE were improved after the events.

\subsection{Identification with and imitation of WE accents}

Judging from the means in Table 1 , the top accent participants identified with was $\operatorname{BrE}(M=4.56)$, with AmE $(M=$ 4.50) a close second. This gained supportive evidence from participants' impressions of the six accents and their corresponding speakers as reflected by 18 traits in Table 2 . The traits were classified into three dimensions, i.e., power, solidarity and competence, following Bayard et al. (2001). BrE received higher ratings than AmE on all the traits except 'reliable' and 'competent', both belonging to competence. Overall, RP and its speaker were assigned greater power, solidarity and competence than other WE accents and speakers. 
Table 1. Participants' identification with and imitation of six WE accents

\begin{tabular}{lcccccc}
\hline & $\mathrm{AuE}$ & $\mathrm{ChE}$ & $\mathrm{AmE}$ & $\mathrm{InE}$ & $\mathrm{KoE}$ & $\mathrm{BrE}$ \\
\hline Identify with this accent? & 3.72 & 2.94 & 4.50 & 3.83 & 2.41 & 4.56 \\
Want to imitate this accent? & 3.02 & 2.23 & 4.28 & 3.53 & 2.00 & 4.25 \\
\hline
\end{tabular}

Table 2. Attitudinal scores for three dimensions of the WE accents

\begin{tabular}{|c|c|c|c|c|c|c|c|}
\hline \multicolumn{2}{|c|}{ Dimensions / Traits } & $\mathrm{AuE}$ & $\mathrm{ChE}$ & $\mathrm{AmE}$ & $\mathrm{InE}$ & $\mathrm{KoE}$ & $\mathrm{BrE}$ \\
\hline \multirow{6}{*}{$\begin{array}{l}\dot{\bar{d}} \\
\overline{0} \\
0\end{array}$} & Authoritative & 3.16 & 2.66 & 4.66 & 3.64 & 2.52 & 4.83 \\
\hline & Dominant & 3.11 & 2.75 & 4.39 & 3.30 & 2.58 & 4.47 \\
\hline & Controlling & 4.00 & 3.62 & 4.42 & 3.89 & 3.30 & 4.56 \\
\hline & Assertive & 3.52 & 2.78 & 4.92 & 4.00 & 2.17 & 5.11 \\
\hline & Powerful & 3.27 & 2.84 & 4.53 & 3.81 & 2.38 & 4.66 \\
\hline & Strong & 2.91 & 2.67 & 4.44 & 3.80 & 2.41 & 4.95 \\
\hline \multirow{6}{*}{ 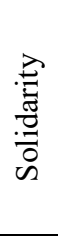 } & Humorous & 2.20 & 2.25 & 2.60 & 3.45 & 2.20 & 3.11 \\
\hline & Cheerful & 2.88 & 2.55 & 2.98 & 3.50 & 2.20 & 3.34 \\
\hline & Friendly & 4.14 & 3.84 & 3.58 & 3.97 & 3.17 & 3.77 \\
\hline & Warm & 3.00 & 2.48 & 3.19 & 3.47 & 2.20 & 3.61 \\
\hline & Pleasant & 3.13 & 2.67 & 3.58 & 3.70 & 2.38 & 3.91 \\
\hline & Attractive & 3.25 & 2.70 & 4.19 & 3.73 & 2.28 & 4.42 \\
\hline \multirow{6}{*}{ 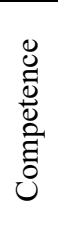 } & Reliable & 4.16 & 3.34 & 4.78 & 4.14 & 2.89 & 4.75 \\
\hline & Ambitious & 2.44 & 2.41 & 4.38 & 3.59 & 2.30 & 4.84 \\
\hline & Competent & 3.53 & 2.92 & 4.81 & 4.00 & 2.52 & 4.81 \\
\hline & Intelligent & 3.86 & 3.02 & 4.47 & 4.00 & 2.81 & 4.64 \\
\hline & Hardworking & 3.62 & 3.42 & 4.06 & 3.98 & 3.03 & 4.45 \\
\hline & Educated & 4.23 & 3.47 & 4.73 & 4.27 & 3.08 & 4.84 \\
\hline
\end{tabular}

Researchers from different cultural contexts have reported that RP is perceived as the highest status variety of English amongst native and non-native speakers of English (see Ladegaard \& Sachdev, 2006). In China, RP has traditionally been regarded as an unsurpassed prestige variety of English, and extensively been adopted as the model of pronunciation at English class. According to our concurrent investigation of 13 English Phonetics quality courses offered to tertiary-level English majors and constructed from 2004 to 2014 on national, provincial and collegiate levels, 12 courses claimed to use or refer to RP-oriented textbooks, either introduced as original editions or compiled by Chinese scholars themselves, e.g., Ship or Sheep? An Intermediate Pronunciation Course (Baker, 2007) and English Pronunciation and Intonation for Communication (Wang, 2005). Undoubtedly, high frequency of exposure to BrE in class enables students to take positive attitudes toward the RP accent and British speakers.

Although they thought highly of BrE, our participants aimed at imitating $\operatorname{AmE}(M=4.28)$ rather than $\operatorname{BrE}(M=4.25)$ (Table 1). This result aligned with the general attitudinal pattern depicted by previous studies (e.g., $\mathrm{He} \& \mathrm{Li}, 2009 ; \mathrm{Hu}$, 2004, 2005; Kirkpatrick \& Xu, 2002; Xu \& Gao, 2014; Zhou \& Chen, 2008), namely, university learners of China are ready to imitate AmE. The student preference for AmE can be partially attributed to its high ethnolinguistic vitality, as evidenced by the rise of economic, political, military and cultural power of the USA in the early part of the $20^{\text {th }}$ century (Ladegaard \& Sachdev, 2006) and the following facts mentioned by Hu (2004). Nowadays it is fashionable for Chinese to speak AmE; huge populations of Chinese students go to the USA for further studies and there is a long line of immigrants from China to the USA. Seven of our interviewees identified with BrE, but opted to imitate AmE. Their viewpoints are summarized in detail.

1) More Americans are recruited as English teachers on university campus. Contact with them in and outside of class familiarizes students with $\mathrm{AmE}$ and arouses their interest in this accent.

2) AmE is easier to imitate. Admittedly, the British accent is standard and elegant, but students feel it challenging to handle. A girl (Participant No. 42, 19 years) recounted how she and her partners entered for a campus dubbing contest. They originally hoped to try a scene of the British TV series Downton Abbey, but finally had to give it up and dubbed a clip of The Little Mermaid, a Disneyland animation, as in her words (our translations), 'AmE sounds casual and liaison is always allowed, but in BrE you need to clearly articulate every vowel and modulate falling and rising intonations, which is so difficult and tiring.' For this, Chinese scholars (e.g., Ding, 1992) explain that AmE has a trend of simplification in terms of pronunciation and the phonemes differentiating between $\mathrm{AmE}$ and $\mathrm{BrE}$ happen to be of difficulty for Chinese learners. For instance, it is troublesome for Chinese learners to distinguish $/ \mathfrak{~} /$ from /e/, but such a distinction is unnecessary and negligible in AmE where Mary can be pronounced as /mæri/ or $/ \mathrm{meri} /$.

3) AmE has found its way into the mass media of China in forms of Hollywood movies, sitcoms (e.g., Friends, The Big Bang Theory), Voice of America programs, and pop music, etc. It is common practice for English majors to develop their English listening and oral skills or pick up idiomatic expressions while immersed in these entertainments. A boy (Participant No. 31, 19 years) told us that he was attempting to learn English by watching original movies and listening to English songs. 
4) American culture is more appealing to students. Despite their interest in cultures of the English-speaking countries, students are comparatively more fascinated by American culture. As youngsters, they admire the essence of freedom and independence deeply rooted in American culture transmitted through school-taught courses or the mass media, which is elucidated by the comments from two interviewees:

American culture is much more relaxing. When we have a western dinner, we don't pay attention to western etiquettes, but British people usually care much about table manners and proper behavior (Participant No. 64, female, 19 years).

As English majors, we couldn't learn this language without being influenced by what's behind it...I find myself thinking the way they [native English speakers] do. When dating with my boyfriend, I insist on going Dutch. He feels like my mind is sort of westernized, because it's a tradition for boys to pay bills in China (Participant No. 29, female, 20 years).

In one word, there was a general desire to adopt the American accent as a role model and meanwhile, a preference for American culture among our participants. Thus this study is more supportive of the language-culture consonance hypothesis than the language-culture discrepancy hypothesis. The former hypothesis suggests a correlation between culture and language, i.e., preference for a particular culture would be associated with a preference for the language of that culture (Ladegaard \& Sachdev, 2006, p. 94).

It is known from Tables 1 and 2 that the participants neither identified with $\operatorname{ChE}(M=2.94)$ nor favored imitating it $(M$ $=2.23$ ). ChE was rated the fifth in all six accents and just evaluated more positively than KoE on three dimensions, implying participants' negative impressions of this accent. The result coincides with what other studies have reported. For example, Hu's (2004) investigation of 490 English majors in China reveals that only 2.3\% of the participants preferred ChE, as compared to $71.6 \%$ in favor of AmE.

An interesting result of this study is pertinent to $\mathrm{InE}$, which achieved a higher degree of identification and willingness of imitation than AuE, an IC variety. Relative to other accents, the Indian accent was upgraded on two traits of the solidarity dimension: 'humorous' and 'cheerful' (see Table 2). However, when seven typical students were invited for interviews and each played InE and AuE, six of them expressed an intention to identify with and imitate AuE instead of InE as they previously chose in the attitudinal experiment. This may be attributable to two reasons. First, when InE was mixed up with other accents, some participants $(N=25,39.1 \%)$ mistook it for an IC accent. Second, although AuE sounds fluent and melodious, InE is close to everyday life and fit for student communication. This opinion was passed by the single interviewee (Participant No. 41, male, 19 years) who confirmed his readiness to accept and imitate InE.

3.3 Perceptions of WE accents in English phonetics instruction

Table 3 registers how the participants responded to seven questions concerning WE accents and English phonetics instruction, five of which (Questions 2 to 6) were multiple-choice questions.

Table 3. Participants' responses concerning WE accents in English phonetics instruction

\begin{tabular}{|c|c|c|c|}
\hline Questions & Options & Response & \%age \\
\hline 1. What is your goal for & Want to achieve native-like pronunciation & 52 & 81.2 \\
\hline \multirow[t]{4}{*}{ English pronunciation? } & Retain pronunciation features of the Chinese & 3 & 4.7 \\
\hline & Pronounce clearly enough to be intelligible to others & 6 & 9.4 \\
\hline & Pass the English phonetics course exam & 2 & 3.1 \\
\hline & Have no definite goal & 1 & 1.6 \\
\hline \multirow{8}{*}{$\begin{array}{l}\text { 2. Which accents do you } \\
\text { think are standard? }\end{array}$} & British English & 53 & 82.8 \\
\hline & China English & 0 & 0 \\
\hline & Canadian English & 7 & 10.9 \\
\hline & Singaporean English & 0 & 0 \\
\hline & New Zealand English & 1 & 1.6 \\
\hline & Australian English & 3 & 4.7 \\
\hline & Indian English & 0 & 0 \\
\hline & American English & 49 & 76.6 \\
\hline \multirow{10}{*}{$\begin{array}{l}\text { 3. Which accents do you } \\
\text { prefer to imitate in } \\
\text { English phonetics } \\
\text { learning? }\end{array}$} & British English & 41 & 64.1 \\
\hline & China English & 4 & 6.3 \\
\hline & Canadian English & 7 & 10.9 \\
\hline & Singaporean English & 1 & 1.6 \\
\hline & New Zealand English & 1 & 1.6 \\
\hline & Australian English & 10 & 15.6 \\
\hline & Indian English & 1 & 1.6 \\
\hline & American English & 52 & 81.3 \\
\hline & Other Englishes & 1 & 1.6 \\
\hline & No preferences & 4 & 6.3 \\
\hline \multirow{4}{*}{$\begin{array}{l}\text { 4. Which accents do you } \\
\text { want to be taught in at } \\
\text { English phonetics class? }\end{array}$} & British English & 40 & 62.5 \\
\hline & American English & 56 & 87.5 \\
\hline & Typical pronunciation features of China English & 6 & 9.4 \\
\hline & Typical pronunciation features of other Englishes & 3 & 4.7 \\
\hline
\end{tabular}




\begin{tabular}{llrr}
\hline $\begin{array}{l}\text { 5. What kind of teacher } \\
\text { do you like to be taught } \\
\text { by at phonetics class? }\end{array}$ & Chinese teachers & 20 & 31.3 \\
F. Where do you like & Foreign teachers from English-speaking countries & 58 & 90.6 \\
your foreign teachers to & UK & 1 & 1.6 \\
\hline come from? & Canada & 50 & 78.1 \\
& Australia & 58 & 90.6 \\
& New Zealand & 37 & 57.8 \\
& Other countries & 18 & 28.1 \\
& Accept it & 9 & 14.1 \\
\hline 7. Do you accept China & Accept it until English is widely used in China & 3.1 \\
English as a variety of & Accept it, but not as the model for phonetics teaching & 17 & 26.6 \\
English around the & Never & 9 & 14.1 \\
world? & Have no ideas & 34 & 53.1 \\
& & 2 & 3.1 \\
\hline
\end{tabular}

Among the participants, $81.2 \%$ wanted to attain native-like pronunciation. Speaking of standard accents, BrE $(82.8 \%)$ was the first choice, and AmE (76.6\%) was the second. The participants tended to imitate IC accents; AmE (81.2\%) headed the list, followed by BrE (64.1\%), AuE (15.6\%) and Canadian English (10.9\%). They mostly hoped to be taught in $\mathrm{AmE}(87.5 \%)$ and $\mathrm{BrE} \mathrm{(62.5 \% )} \mathrm{at} \mathrm{English} \mathrm{phonetics} \mathrm{class.} \mathrm{90.6 \%} \mathrm{welcomed} \mathrm{natives} \mathrm{from} \mathrm{English-speaking} \mathrm{(IC)}$ countries as their phonetics teachers, particularly those from the USA (90.6\%), the UK (78.1\%) and Canada (57.8\%). Meanwhile, $31.2 \%$ also welcomed Chinese teachers. With regard to the attitudes toward $\mathrm{ChE}, 26.6 \%$ of our participants accepted $\mathrm{ChE}$ as a new variety. Over half of them (53.1\%) accepted it, but considered that it should not be a phonetics teaching model.

Six of our interviewees once worked as volunteers for the $2^{\text {nd }}$ Nanjing Youth Olympic Games in August, 2014. We narrowly examined their attitudinal changes to WE accents and found that this intercultural communication event cultivated their sense of WE, developed their permissive attitude toward accented English spoken by people from OC and EC countries, and enhanced their national pride in ChE. Despite that, the six interviewees unanimously expressed their unchanged attitudes to imitate $\mathrm{AmE}$ or BrE, as these two accents are pleasant to the ear, understandable and remain in the mainstream; furthermore, native-like pronunciation is a hallmark of success for English learning. See their comments below:

I don't think English just belongs to the UK or the USA. Every country can use its own English for communication. English is no more than a tool, not a symbol of a particular country (Participant No. 48, female, 19 years).

Once I met a delegation member asking the way where was number 21 [pillar signifying the road sign of Nanjing Olympic Sports Center Venue Cluster]. He had a heavy accent, unable to pronounce the word 'one' clearly in English, but that's ok...it's my own business to imitate BrE or AmE so as to improve my oral English, but I see no reason for others to follow suit (Participant No. 42, female, 19 years).

The result is consistent with that of Xu and Gao (2014) mentioned above. They scrutinized students' attitudes toward five WE varieties before and after four international events, and discovered an increased identification with ChE on one hand, but stable stereotypes on the other - after the events AmE and BrE were still far more favorably evaluated than ChE.

In general, our participants were attitudinally oriented to AmE and BrE. This adds empirical evidence to Pei (2014). After analyzing the feasibility of the nativised model and the lingua franca model within the context of China, she argued that the native speaker model should still be kept in use in current China's English phonetics instruction. The leading reason is that English teachers and learners of China attitudinally value and accept AmE and BrE. Actually, the native speaker model is equally popular in other EC countries. Kang (2015) reported on English learners' perceptions of pronunciation lessons and their attitudes toward instructors' accent varieties in three circles of WE, with 185 participants coming from EC countries Japan and Korea. As a result, approximately $85 \%$ of the EC respondents strove for IC norms (i.e., RP and GA) in their pronunciation and expressed their desire to sound like a native English speaker.

\section{Conclusion}

This study yielded the major findings as follows. Tertiary-level English majors in China could recognize AmE and BrE better. They identified with BrE most and deemed it a standard accent, but preferred to imitate AmE and welcome natives from the USA as their English phonetics teachers. They failed to recognize ChE well when it was mixed up with other EC accents. Additionally, they showed no identification with $\mathrm{ChE}$ or willingness to imitate it. For those who experienced international events, their favorable evaluations of $\mathrm{AmE}$ and $\mathrm{BrE}$ remained unchanged. On balance, English majors were strongly inclined to set a native speaker norm for their own speech, opposed to adopting ChE as a model for English phonetics instruction.

In the contexts of globalization and English as a lingua franca, scholars are increasingly calling for a shift from the native speaker model to the lingua franca model. The former seems not to be a realistic pronunciation model for English 
learners in EC countries, while the latter features mutual intelligibility which has become a key criterion for both speakers and listeners in speech. However, the results of this study indicate that nowadays teachers for English majors in China still need to adhere to the native speaker model in their English phonetics instruction. While allowing learners to pursue a native-like accent in their production, teachers are also advised to expose them to various WE accents so that they could recognize different accents and understand people from non-IC countries in intercultural communications.

Though carefully designed and conducted, this study is not without its limitations. Its participants were all sophomores majoring in English at the same university of China. Their homogeneous nature may pose a problem when we attempt to generalize the findings obtained. The number of participants was also relatively small. In the future, researchers may consider surveying a larger sample of English majors at different grades from several universities. They may include non-English majors for comparing whether their attitudes toward WE accents and expectations of English phonetics instruction are dissimilar or similar to English majors'. It is hoped that more studies will be made in EC countries to capture English learners' attitudinal changes toward accent varieties of English so that teachers can decide on their English phonetics teaching model accordingly to facilitate their students' phonetics learning.

\section{References}

Baker, A. (2007). Ship or sheep? An intermediate pronunciation course ( $3^{\text {rd }}$ ed.). Cambridge: Cambridge University Press.

Bayard, D., Weatherall, A., Gallois, C., \& Pittam, J. (2001). Pax Americana? Accent attitudinal evaluations in New Zealand, Australia and America. Journal of Sociolinguistics, 5(1), 22-49. doi:10.1111/1467-9481.00136, http://dx.doi.org/10.1111/1467-9481.00136.

Dai, Y. (2000). Phonetic features of Indian English. Journal of PLA University of Foreign Languages, 23(6), 58-60.

Ding, P. (1992). The differences between General British English and General American English. Foreign Language Teaching and Research, (1), 63-67.

Gao, Y., \& Lin, M. (2008). The attitude towards World Englishes among volunteers of Olympic Games. Journal of Xinjiang Normal University, 29(4), 86-92.

He, D. Y., \& Li, D. C. S. (2009). Language attitudes and linguistic features in the 'China English' debate. World Englishes, 28(1), 70-89. doi: 10.1111/j.1467-971X.2008.01570.x, http://dx.doi.org/10.1111/j.1467-971X.2008.01570.x.

$\mathrm{Hu}$, X. (2005). China English, at home and in the world. English Today, 21(3), 27-38. doi:10.1017/S026607840500307X, http://dx.doi.org/10.1017/S026607840500307X.

$\mathrm{Hu}, \mathrm{X}$. (2004). Why China English should stand alongside British, American, and the other World Englishes. English Today, 20(2), 26-33. doi: 10.1017/S0266078404002056, http://dx.doi.org/10.1017/S0266078404002056.

Kang, O. (2015). Learners' perceptions toward pronunciation instruction in three circles of World Englishes. TESOL Journal, 6(1), 59-80. doi: 10.1002/tesj.146, http://dx.doi.org/10.1002/tesj.146.

Kirkpatrick, A., \& Xu, Z. C. (2002). Chinese pragmatic norms and 'China English'. World Englishes, 21(2), $269-279$. doi: 10.1111/1467-971X.00247, http://dx.doi.org/10.1111/1467-971X.00247.

Ladegaard, H. J., \& Sachdev, I. (2006). I like the Americans...but I certainly don't aim for an American accent: Language attitudes, vitality and foreign language learning in Denmark. Journal of Multilingual and Multicultural Development, 27(2), 91-108. doi:10.1080/01434630608668542, http://dx.doi.org/10.1080/01434630608668542.

Pei, Z. (2014). The theory, choice and thinking on English phonetics teaching model. Foreign Language World, (3), 8896.

Weinberger, S. (2014). Speech accent archive. [Online] Available: http://accent.gmu.edu (March 27, 2016)

Xu, H., \& Gao, Y. (2014). The attitudes of Chinese student volunteers toward World Englishes before and after four intercultural communication events. Foreign Language Education in China, 35(1), 43-48.

Wang, G. (2005). English Pronunciation and Intonation for Communication (2 ${ }^{\text {nd }}$ ed.). Beijing: Higher Education Press.

Zhou, R., \& Chen, G. (2008). A study of Chinese university students' attitude to American and British English. Modern Foreign Languages, 31(1), 49-57. 